\title{
Políticas sociais e pobreza no Brasil: desafios em direção ao desenvolvimento humano
}

Social policies and poverty in Brazil: challenges towards human development

\author{
Darcy Ramos da Silva Neto \\ netodarcy25@gmail.com \\ Universidade Federal de Santa Maria (UFSM)
}

\author{
Sibele Vasconcelos de Oliveira \\ sibele.ufsm@gmail.com \\ Universidade Federal de Santa Maria (UFSM)
}

Resumo: A literatura acadêmica acerca da pobreza é plural, sendo que as concepções contemporâneas apontam para a importância das abordagens multidimensionais do fenômeno, bem como de suas políticas de enfrentamento. O presente estudo tem por objetivo desenvolver uma análise da construção do conceito de pobreza, assim como avaliar as condições das políticas sociais brasileiras em promover o desenvolvimento humano e a superação das desigualdades sociais. Para tanto, foram realizadas pesquisas bibliográficas e documentais, a coleta e análise de dados secundários sobre desenvolvimento no Brasil atual. Desde a implementação do PBF, foi possível constatar avanços expressivos em termos de diminuição do número de pessoas em situação de extrema pobreza. Apesar das conquistas sociais, muitos são os desafios a serem superados. Destarte, argumenta-se que as políticas sociais podem ser instrumentos interessantes no controle das fontes de privação da população.

Palavras-chave: Desenvolvimento humano; Política social; Privações

\begin{abstract}
The academic literature on the phenomenon of poverty is plural, being that contemporary conceptions point to the importance of multidimensional approaches to poverty, as well as its coping policies. The present study aims to develop an analysis of the construction of the concept of poverty, as well as to evaluate the conditions of Brazilian social policies in promoting human development and overcoming social inequalities. For this purpose, bibliographical and documentary research was carried out, the collection and analysis of secondary data on social development in actual Brazil. Since the implementation of the PBF, it has been possible to see significant advances in terms of reducing the number of people living in extreme poverty in Brazil. In spite of the social achievements, many are the challenges to be overcome, among these, it is mentioned the fall in the index of human development of the country. Thus, it is argued that social policies can be interesting tools for controlling the deprivation of the population.
\end{abstract}

Keywords: Human Development; Social policy; Deprivation 


\section{INTRODUÇÃO}

A má distribuição de renda e os elevados níveis de pobreza fazem do Brasil um dos países mais desiguais do mundo. Os dados disponibilizados pelo Relatório de Desenvolvimento Humano, desenvolvido pelas Nações Unidas, mostram que o Brasil ocupa a décima posição dentre os países com maior disparidade de renda (ONU, 2017).

De acordo com a Organização das Nações Unidas para Agricultura e Alimentação (FAO, 2014), embora o país tenha deixado de compor o chamado "mapa da fome" ${ }^{1}$ no ano de 2014, ainda 3\% da população brasileira ingere menos calorias do que o recomendado. Este cenário de mazela social demanda dos agentes públicos ações em prol do desenvolvimento humano.

Sobretudo, salienta-se que a pobreza tem um caráter plural e complexo, não podendo ser abordada pelos entes públicos com estratégias unilaterais sobre os quesitos renda ou riqueza (SEN, 2010). Destarte, assume-se a perspectiva multidimensional do fenômeno, a qual reconhece que a vida dos indivíduos é influenciada por diversas dimensões além da monetária, a citar, as dimensões relacionadas ao acesso à saúde, à educação, entre outros fatores relevantes ao bem-estar social (SEN, 2010).

Definir as dimensões analíticas da pobreza não é uma tarefa trivial, pois não há consenso entre os estudiosos sobre quais são os espaços de análise ou variáveis focais indispensáveis ao entendimento do fenômeno. De fato, cada sociedade possui suas especificidades, sendo que as dimensões valoradas por cada uma diferem sobremaneira.

Sendo assim, a presente pesquisa tem por objetivo analisar as características das principais discussões e abordagens acerca da pobreza. Realiza-se um estudo sobre os esforços de mensuração e de identificação das variáveis influentes sobre o referido conceito. Desse modo, a redação foi organizada de forma a apresentar uma perspectiva geral das teorias que exploram os conceitos relacionados à pobreza e suas múltiplas formas, com foco na realidade do Brasil.

Ademais, exploram-se as políticas públicas implementadas nas últimas décadas, observando o modo de vida de milhões de brasileiros vivendo em situação de vulnerabilidade social. Assim, busca-se desvendar como a pobreza vem sendo tratada pelas políticas sociais de promoção do desenvolvimento humano, além de explorar os desafios para o Brasil contemporâneo.

\footnotetext{
${ }^{1} \mathrm{O}$ "mapa da fome" faz referência ao conjunto de países que têm mais de $5 \%$ da população ingerindo menos calorias diárias que o recomendável (FAO, 2014).
} 


\section{ENTÃO, O QUE É POBREZA?}

Para Chambers (2006), a construção do significado do conceito de pobreza depende de três fatores: quem efetua a pergunta, como esta é entendida e, por fim, como esta é respondida. Desta forma, pode-se considerar que a definição de pobreza é nebulosa, relativa e complexa. Sobretudo, trata-se de um conceito em construção, cujos pressupostos diferem de acordo com os valores e princípios sociais compartilhados (AZEVEDO; BURLANDY, 2010).

Rocha (2006) corrobora o entendimento de que a pobreza é um fenômeno complexo, contudo a conceitua como uma situação na qual as necessidades dos indivíduos não são atendidas de forma adequada. Assim, diz-se que a definição de pobreza está associada à análise do padrão de vida dos indivíduos e na forma como suas demandas são atendidas frente a determinado contexto socioeconômico.

Vale destacar que as múltiplas abordagens da pobreza contemplam conceitos monetários, não monetários e sociais, incluindo direitos, representatividade e liberdade dos indivíduos. É necessário conhecer o aspecto sistêmico destes conceitos para que se possa compreender as perspectivas plurais desenvolvidas por pesquisadores e suas consequentes divergências, especialmente no que tange aos esforços em mensuração dos graus de pobreza de uma sociedade (SEN, 2010).

Townsend (2006) salienta que, desde a década de 1880, três concepções alternativas de pobreza têm evoluído como base para o trabalho internacional e comparativo. Estas concepções embasam-se principalmente nas ideias de subsistência, necessidades básicas e privação relativa.

Em especial, a ideia de subsistência surgiu na Europa durante os anos 1890, e estava correlacionada à noção do "mínimo para sobrevivência física"2. Conforme esta abordagem, os indivíduos podem ser considerados pobres quando suas rendas são insuficientes para obter os bens materiais necessários para manter sua sobrevivência física (TOWNSEND, 2006).

Townsend (1993) argumenta que existe um problema potencial no uso da noção de subsistência para definir o que é a pobreza. De acordo com o autor, as necessidades humanas não podem ser consideradas como físicas, exclusivamente. Os homens são seres que requerem de energia para sua força vital, mas também são seres com desempenhos sociais múltiplos.

The main problem of the 'subsistence' concept can be semmarised as being that human needs are interpreted as being physical needs - for food, shelter and clothing -

\footnotetext{
${ }^{2}$ Sob esta perspectiva, as necessidades do indivíduo eram comumente medidas pela sua capacidade de acesso à alimentação (TOWNSEND, 1993).
} 
rather than as being social needs, and yet the crucial fact about human beings is that they are social beings rather than physical beings. It is through social relationships and social roles that needs arise. This comes from being parents, partners, neighbours, friends and citizens, for example. People are not only consumers, therefore, but leaders, active participants and producers (TOWNSEND, 1979, p. 31).

Destarte, em 1970 surge a concepção de análise da pobreza como vinculada ao conceito das necessidades básicas, a qual agrega duas dimensões à perspectiva da subsistência: as necessidades mínimas de consumo das famílias (relacionadas ao acesso a alimentos, vestuários, entre outros bens e serviços) e o acesso aos serviços essenciais disponíveis às comunidades (a saber, o acesso à habitação, água, saneamento básico, educação, saúde, transportes e serviços culturais) (TOWNSEND, 1979; 2006).

Segundo a Organização Internacional do Trabalho (OIT, 1976), a avaliação do conceito de necessidades básicas deve ser realizada à luz do contexto do desenvolvimento econômico e social das nações. No relatório "Employment Growth and Basic Needs: A OneWorld", a referida instituição argumenta que:

The concept of basic needs should be placed within a context of a nation's overall economic and social development. In no circumstances should it be taken to mean merely the minimum necessary for subsistence; it should be placed within a context of national independence, the dignity of individuals and peoples and their freedom to chart their destiny without hindrance (OIT, 1976, p. 24-25).

O conceito de necessidades básicas desempenhou um papel proeminente nos planos nacionais de desenvolvimento promovidos pela comunidade internacional, especialmente os agenciados pela Organização das Nações Unidas. É a partir desta perspectiva que se explicita o caráter multidimensional da vida humana e do próprio fenômeno da pobreza. Da mesma forma, é sob esta mesma concepção que se asseveram as indagações sobre como proceder com a eleição de quais são as necessidades básicas de cada sociedade, considerando suas especificidades, já que estas variam de uma localidade para outra (AZEVEDO; BURLANDY, 2010).

Ao final do século XX, uma terceira noção da pobreza foi desenvolvida, a saber, a de privação relativa. $\mathrm{O}$ termo relatividade aplica-se tanto à privação da renda quanto à privação de outros recursos materiais e de acesso aos serviços sociais. Como resultado desta abordagem, pobres são os indivíduos desprovidos de renda e de outros tipos de recursos, que permitem com que tenham uma condição de vida adequada. Portanto, incluem-se na análise ${ }^{3}$

\footnotetext{
${ }^{3}$ Segundo Crespo e Gurovitz (2002), a superação da pobreza, sob a concepção relativa, prevê o acesso por parte dos indivíduos a um regime alimentar adequado, certo nível de conforto, o desenvolvimento de papéis e de comportamentos socialmente adequados.
} 
as condições necessárias para que os indivíduos participem das atividades da vida em sociedade, cumpram suas obrigações e estabeleçam relações sociais (TOWNSEND, 1979; 2006).

Ressalta-se que a noção de pobreza relativa é estabelecida em consonância ao contexto social dos indivíduos, ponderando-se o padrão de vida e a maneira como suas diversas necessidades são contempladas em uma dada realidade socioeconômica. Desse modo, a pobreza relativa é estabelecida por comparação: o fenômeno é entendido como um estado de carência relativamente a outras situações sociais com que é confrontado (CODES, 2008).

Rocha (2006) elucida que o exercício da definição da pobreza relativa está diretamente relacionado ao ato de delimitar um conjunto de indivíduos "relativamente pobres" em sociedades onde o mínimo vital já é garantido a todos. Portanto, a pobreza relativa vincula-se frequentemente ao grau de distribuição de renda e costumes de determinada localidade. Como exemplo da definição de linha de pobreza relativa, cita-se o parâmetro estabelecido pelos países da Organização de Cooperação e de Desenvolvimento Econômico (OCDE). Para OCDE, a linha de pobreza é calculada através do critério " $50 \%$ do valor da mediana da renda per capita". Dessa forma, a quantidade de pobres existente em determinada sociedade está sempre associada à distribuição de renda do próprio país.

Codes (2008) evidencia que a formulação do significado da pobreza relativa é consequência do reconhecimento, por parte dos pesquisadores, da interdependência entre o fenômeno da pobreza e as estruturas social e institucional vigentes. Esta mudança de perspectiva traduz-se na consideração de um maior conjunto de indicadores observáveis de privações sociais e materiais, além da avaliação da relação entre as distintas privações ao longo do tempo e sob as condições territoriais influentes sobre o fenômeno.

O enfoque da privação relativa evoluiu substancialmente com as contribuições do indiano Amartya Sen, vencedor do prêmio Nobel de Economia no ano de 1998. Sua abordagem introduz variáveis amplas e de múltiplas origens, chamando a atenção para o fato de que as pessoas podem sofrer privações em diversas esferas da vida. Sob esta concepção, ser pobre não implica apresentar somente privação material ou privação de renda, mas também privações no tocante ao posicionamento como cidadãos na sociedade (CRESPO; GUROVITZ, 2002).

Segundo Sen (2010), as privações são vistas em um nível próximo das demandas informacionais da justiça social. Sendo assim, a pobreza deve ser interpretada como privações de capacidades básicas, ao invés de meramente como baixo nível de renda, que é o critério tradicional de identificação deste fenômeno. 
Sob a perspectiva das capacidades, Amartya Sen desenvolveu inúmeros estudos que explicitam a natureza e as causas da pobreza. Com ênfase sobre os fins que os indivíduos têm por objetivo buscar e, consequentemente, sobre as liberdades de poder alcançar esses fins, o autor desvia a atenção dos meios (perspectiva da renda), desenvolvendo uma análise plural e multidimensional do fenômeno da pobreza.

A conceituação de liberdade dos indivíduos, para Sen (2010), é complexa e faz referência às múltiplas oportunidades que cada pessoa tem de exercer suas atividades, o direito à visualização de outras e novas perspectivas para suas vidas. Em termos gerais, o indivíduo é considerado livre em suas capacidades quando consegue vislumbrar que existem outros caminhos para seu sucesso pessoal e profissional, perante a si mesmo e perante a sociedade em que vive.

Sen (2010) desenvolve o conceito de pobreza como associado à noção de privação das capacidades básicas. Em síntese, a abordagem das capacidades pressupõe que cada indivíduo está provido de determinada dotação de recursos, que define os intitulamentos (entitlements ${ }^{4}$ ) que ele poderá intercambiar. Assim, os indivíduos detentores desses intitulamentos estão aptos a obter determinados bens alcançáveis, ou que possam ser adquiridos.

Daí decorre a ideia de privações, uma vez que é a partir do efetivo vetor de funcionamentos ${ }^{5}$ que são estabelecidos os níveis de bem-estar e de pobreza do conjunto da sociedade. A pobreza consiste em maximizar a privação das capacitações das pessoas, o não acesso, a exclusão do indivíduo aos intitulamentos. Logo, a privação de capacidades básicas pode refletir-se em morte prematura, subnutrição considerável, morbidez, analfabetismo e outras mazelas sociais (SEN, 2010).

A renda inadequada é um forte indicativo das condições de privação de uma pessoa pobre. Todavia, além da renda, existe a preocupação com a privação das condições para realizar funcionamentos, que é o traço primário do aspecto do bem-estar (SEN, 2012). Destarte, considera-se que a renda é um argumento instrumental usado para avaliar a pobreza, mas não a definição por si só.

Os argumentos em favor da abordagem da pobreza como privação de capacidades são apresentados por Sen (2010) no livro "Desenvolvimento como Liberdade". De acordo com o autor:

\footnotetext{
${ }^{4}$ Entitlements incluem capacidades aplicadas ao espaço de mercado. A capacidade de uma pessoa é "um conjunto de pacotes alternativos de funcionamento. Portanto, o intitulamento é "um conjunto de pacotes alternativos de mercadorias" (SEN, 2012, p. 235).

${ }^{5}$ Segundo Sen (2012, p. 236), os funcionamentos referem-se a atividades, estados de existência ou ser (tais como: comer, estar bem nutrido, não estar envergonhado pela simplicidade da roupa vestida, entre outros).
} 
1) A pobreza pode sensatamente ser identificada em termos de privação de capacidades; a abordagem concentra-se em privações que são intrinsecamente importantes (em contraste com a renda baixa, que é importante apenas instrumentalmente).

2) Existem outras influências sobre a privação de capacidades - e, portanto, sobre a pobreza real - além do baixo nível de renda (a renda não é o único instrumento de geração de capacidades).

3) A relação instrumental entre baixa renda e baixa capacidade é variável entre comunidades e até mesmo entre famílias e indivíduos (o impacto da renda sobre as capacidades é contingente e condicional) (SEN, 2010, p.120-121).

É preciso ressalvar que a abordagem das capacidades não rejeita a ideia de que a renda baixa é um dos condicionantes principais da pobreza. De fato, a ausência de renda pode ser uma razão fundamental da privação de capacidades do indivíduo. Entretanto, existem outras dimensões da vida social que influenciam as condições de privação da pessoa e analisá-las é precondição para uma avaliação fidedigna à realidade social.

Kerstenetzky (2000) salienta que os propósitos humanos vão muito além do simplesmente "ter" (como riqueza, por exemplo), mas sim uma visão de "fazer" e "ser", correspondendo à ideia dos funcionamentos ${ }^{6}$ definidos por Sen (2010). Entretanto, os propósitos de "ter", "fazer" e "ser" são importantes não tanto em si mesmos, mas servem efetivamente como indicadores da liberdade dos indivíduos, o que Sen (2010) trata como capacidades.

Ademais, Sen (2010) evidencia que as duas perspectivas, a saber, a pobreza como baixo nível de renda e a pobreza como inadequação de capacidades, não deixam de estar associadas, já que a primeira noção (da perspectiva da renda) é um importante instrumento para se ampliar a segunda (da perspectiva da capacidade). No entanto, é fundamental destacar que a redução da pobreza de renda não pode, em si mesma, ser a motivação exclusiva das políticas de combate à pobreza (SEN, 2010).

Neste sentido, para Sen (2010), a superação da pobreza está vinculada ao ato de dotar os indivíduos de condições humanas. Isto porque, diferentemente da teoria neoclássica do bem-estar social, a noção das capacitações não supõe que as pessoas têm liberdade de fazer escolhas a partir de uma dotação de recursos. Ao contrário, a liberdade deve ser garantida e não suposta. Isso faz com que o aumento das capacidades ajude a enriquecer a vida humana, tornando as privações mais raras e, consequentemente, as pessoas menos pobres (SEN, 2010).

\footnotetext{
${ }^{6}$ Sen (2010) argumenta que os funcionamentos podem variar dos mais elementares, como estar bem nutrido ou escapar da mortalidade prematura, por exemplo, para uma análise mais sofisticada entre ser capaz de se tornar parte na vida de uma comunidade e criação de respeito próprio.
} 
Azevedo e Burlandy (2010) afirmam que, por ser complexa e multidimensional, a abordagem da pobreza como privação de capacidades suscita questionamentos acerca dos pressupostos a serem pautados quando da formulação de estratégias de combate à sua superação. De acordo com os autores:

\begin{abstract}
O primeiro deles é a importância de um profundo conhecimento dos contextos locais, considerando que os determinantes da pobreza podem ser muito distintos, especialmente em países como o Brasil. Outra questão é a necessidade de uma abordagem integral do problema, ou seja, ações que afetem as múltiplas dimensões da pobreza e que sejam integradas e convergentes nos seus usuários potenciais, de forma a se adequarem às suas necessidades. Com efeito, esta abordagem indica a necessidade da conjunção de diferentes tipos de ações e sua integração a uma política que considere intervenções de curto, médio e longo prazo (AZEVEDO; BURLANDY, 2010, p. 204).
\end{abstract}

Neste ínterim, considerando que a pobreza é um fenômeno observável ao longo da história de formação do Brasil $^{7}$, busca-se explorar a importância dos programas sociais no combate às situações de vulnerabilidade vivida pelos brasileiros. A próxima seção aborda um panorama geral de como os programas sociais podem contribuir positivamente ao combate da pobreza em países caracterizados pela desigualdade social, tal como o Brasil.

\title{
3. PROGRAMAS SOCIAIS DE COMBATE À POBREZA NO BRASIL CONTEMPORÂNEO
}

O combate à privação de liberdades e às desigualdades sociais está na agenda política de muitos países desde meados do século XX. Especialmente, cita-se a construção da Declaração do Milênio das Nações Unidas, realizada no ano de 2000 por 191 estados membros, que definiu os Objetivos de Desenvolvimento do Milênio. Constituída por compromissos assumidos pelas diversas organizações e instituições públicas, se cumpridos nos prazos fixados, deveriam melhorar a qualidade de vida e o bem-estar social no século vigente (ONU, 2015).

A Declaração trouxe uma série de objetivos a serem superados, dentre eles, cita-se o primeiro objetivo: a erradicação da pobreza extrema e da fome. A iniciativa da organização é que se possa alterar o cenário atual de vulnerabilidade social, onde se estima que 1.200

\footnotetext{
${ }^{7}$ Martins (2007) ressalta que as mudanças econômicas e sociais, condicionadas pelo rearranjo do mercado capitalista, a regionalização dos mercados e a crescente concentração do capital financeiro, foram responsáveis pelo crescimento da pobreza e das desigualdades sociais no Brasil. Diante deste cenário, crescem as demandas por ações públicas voltadas à proteção social dos indivíduos em situação de privação de liberdades.
} 
milhões de pessoas sobrevivam com menos do que o equivalente a US $\$ 1,00 \mathrm{PPC}^{8}$ por dia (ONU, 2015).

Observa-se que o caminho em direção às conquistas sociais é lento e gradual, mas totalmente viável. No período de 1990 a 2012, enquanto o mundo conseguiu reduzir a pobreza extrema pela metade (de $47 \%$ para $22 \%$, respectivamente), o Brasil erradicou a fome e fez com que a população extremamente pobre do país diminuísse para 3,5\% em 2012 (em comparação aos 25,5\% no ano de 1990) (BRASIL, 2015).

Sendo assim, é possível afirmar que o Brasil realizou grandes conquistas nos últimos anos. Segundo o relatório divulgado pelo Portal Brasil e pelo Programa das Nações Unidas para o Desenvolvimento, o Brasil foi um dos países que mais contribuíram para o mundo alcançar a meta proposta pelo primeiro dos oito objetivos das Nações Unidas (BRASIL, 2015).

A despeito dos avanços no campo social, vale mencionar que os problemas da pobreza, da vulnerabilidade social e econômica não podem ser solucionados simplesmente com programas pontuais e emergenciais (AZEVEDO; BURLANDY, 2010). A formulação e implementação de políticas públicas de enfrentamento a estas mazelas acompanha o movimento de multidimensionalidade do próprio conceito de privação.

Ressalta-se que as políticas sociais vinculadas ao conceito de superação de privação ganham efetividade no Brasil com a promulgação da Constituição Federal de 1988. A, então denominada, "Constituição Cidadã", define o campo da seguridade social como o conjunto integrado de ações voltadas para assegurar os direitos sociais relativos à saúde, previdência e assistência social da população brasileira (CARVALHO, 2008).

Desde a promulgação da Constituição Federal, o Estado brasileiro passou a exercer ativas ações para assegurar que a população em situação de vulnerabilidade possa ter acesso aos direitos previstos em lei. Neste sentido, destaca-se que na virada do século XX, as políticas de transferência de renda condicionadas ganharam particular relevância na agenda nacional (PEÑA et al., 2015).

Ao final dos anos 1990 e início dos anos 2000, foram criados os Programas de Erradicação do Trabalho Infantil, Bolsa Escola e a Bolsa Alimentação. Tendo como públicoalvo a parcela mais empobrecida da população brasileira, estas políticas sociais tinham como objetivo: a) a diminuição da pobreza no curto prazo e b) o combate a sua transmissão intergeracional (PEÑA et al., 2015). Importante destacar que esses benefícios exigiam

\footnotetext{
${ }^{8}$ Dólares medidos pela paridade do poder de compra de cada moeda nacional.
} 
contrapartidas consistentes, principalmente quanto à frequência escolar mínima de $85 \%$ no ano para crianças de 6 a 15 anos, aleitamento materno, exames pré-natais para gestantes e vacinação das crianças (PEÑA et al., 2015, p. 890).

Ainda, Silva et al. (2007) denotam que, no penúltimo ano de governo de Fernando Henrique Cardoso, foi instituído o Cadastro Único dos Programas Sociais do Governo Federal. O Cadastro Único tinha como objetivo cadastrar, com uso de formulário único, as famílias em situação de pobreza e extrema pobreza de todos os municípios brasileiros, de forma que o monitoramento e controle da execução da política social fossem realizados.

Em 2003, já no governo de Luiz Inácio Lula da Silva, foi instituído o Ministério do Desenvolvimento Social e Combate à Fome (MDS, BRASIL, 2015), que incorporou essas políticas em um único programa, de maneira a unificar as ações públicas nas áreas de Assistência Social, Segurança Alimentar e Nutricional, Saúde, Educação Infantil e Transferência de Renda (SILVA et al., 2007). Este evento caracterizou-se por mudanças qualitativas na composição das políticas sociais em prol da superação da pobreza multidimensional.

Cria-se então o Programa Bolsa Família (PBF), constituído pela integração dos benefícios monetários concedidos às famílias em situação de pobreza, em função do número de crianças e adolescentes que as compõem. Buscou-se, assim, superar a fragmentação e o paralelismo dos programas anteriores, bem como a induzir uma sinergia nacional sob uma gestão única (PEÑA et al., 2015).

O Programa Bolsa Família é gerido de forma descentralizada e compartilhada pela União, estados e municípios. De acordo com Mourão e Jesus (2011), atualmente o PBF possui três eixos principais: transferência de renda, condicionalidades e programas complementares.

(...) a transferência de renda busca promover o alívio imediato da pobreza; as condicionalidades reforçam o acesso a direitos sociais básicos nas áreas de educação, saúde e assistência social; e os programas complementares objetivam o desenvolvimento das famílias, de modo que os beneficiários consigam superar a situação de vulnerabilidade (MOURÃO; JESUS, 2011, p. 2).

O Programa Bolsa Família prevê que os beneficiados cumpram com alguns compromissos, caracterizados pelas condicionalidades, as quais têm por objetivo fomentar o acesso de cada indivíduo a seus direitos sociais elementares. Mourão e Jesus (2011) destacam ainda as condicionalidades prevalecentes para assegurar o direito de cada beneficiário do PBF em usufruir a referida política pública: 
a) acompanhar o cartão de vacinação e o crescimento e desenvolvimento das crianças menores de sete anos;

b) as mulheres na faixa de 14 a 44 anos também devem fazer o acompanhamento médico e, se gestantes ou nutrizes, devem realizar o pré-natal e o acompanhamento da sua saúde e do bebê;

c) todas as crianças e adolescentes entre 6 e 15 anos devem estar devidamente matriculados e com frequência escolar mensal mínima de $85 \%$ da carga horária;

d) os estudantes entre 16 e 17 anos devem ter frequência de, no mínimo, 75\%;

e) crianças e adolescentes com até 15 anos em risco ou retiradas do trabalho infantil pelo Programa de Erradicação do Trabalho Infantil devem participar dos Serviços de Convivência e Fortalecimento de Vínculos e obter frequência mínima de $85 \%$ da carga horária mensal (MOURÃO; JESUS, 2011, p. 2).

Cabe citar que a existência das condicionalidades não tem caráter punitivo, mas buscam expandir as oportunidades de exercício da cidadania e de acesso aos direitos por parte dos beneficiários pela política pública. Todavia, caso os indivíduos não cumpram com os critérios acima mencionados, podem ter seus benefícios bloqueados, suspensos ou cancelados.

Para participar do Programa Bolsa Família, além de cumprir com as condicionalidades previstas legalmente, o indivíduo deve atender aos critérios de seleção pautados sob a análise da renda familiar per capita e na distribuição do benefício pelo território brasileiro. Pela análise das informações inseridas por cada município no Cadastro Único para Programas Sociais, dá-se o processo de seleção das famílias a serem beneficiadas pelo PBF (MDS, 2011; MOURÃO; JESUS, 2011).

Uma das dimensões fonte de controvérsias a respeito da operacionalização do Programa Bolsa Família no Brasil, citado que Hoffmann (1998), é a ausência de um critério objetivo para definir a escolha da linha de pobreza, sendo a determinação dos valores monetários bem arbitrários. De acordo com Kerstenetzky e Monçores (2013), em estudo realizado sobre as práticas de gestão do PBF, o percentual de famílias em situação de pobreza e extrema pobreza no país varia de acordo com o critério utilizado para definir a linha de pobreza. Segundo os autores, o PBF utiliza o critério de pobreza absoluta, porém, se for utilizado o critério relativo, os resultados podem apresentar variações bem expressivas.

Para o cálculo, foram utilizados os critérios da OCDE que utiliza duas linhas de pobreza relativa, um critério equivalente a $50 \%$ da renda mediana e outro equivalente a $60 \%$ desta mesma renda. Considerando a realidade brasileira, a renda mediana fica à esquerda da renda média da população, ou seja, abaixo da média. Com base na Pesquisa Nacional por Amostra de Domicílios (2012), o aumento ou diminuição do percentual de pessoas em situação de pobreza varia de acordo com o critério estabelecido (IBGE, 2012; KERSTENETZKY; MONÇORES, 2013). 
A análise dos dados do IBGE (2012) permite observar que o critério de $50 \%$ de renda mediana comprova um percentual de $23,8 \%$ da população na condição de pobreza. Todavia, a alteração do critério de corte para $60 \%$ de renda mediana, o total da população pobre passa para 30,2\% (KERSTENETZKY e MONÇORES, 2013).

Outra controvérsia a respeito dos critérios empregados para definição dos domicílios em situação de pobreza e extrema pobreza, de acordo com o IPEA (2015), é o fato de existir um efeito inflacionário na economia brasileira, que impacta diretamente no percentual de transferência, com tendência de diminuição ao longo do tempo. Em síntese, dentro da primeira década do PBF, o último reajuste dos benefícios ocorreu em abril de 2011. Portanto, a falta de correção monetária anual pode mascarar os resultados do programa. Argumenta-se que a ausência de correção monetária facilita o processo de cumprimento das metas de ampliação da abrangência do PBF, mostrando que muitas famílias "superaram" a condição de miséria apenas pela manutenção do valor nominal da linha de pobreza.

A figura 01 apresenta as taxas de domicílio em situação de pobreza e extrema pobreza no Brasil ao longo dos primeiros anos de execução do Programa Bolsa Família.

Figura 1: Taxa de domicílios em situação de pobreza e extrema pobreza no Brasil

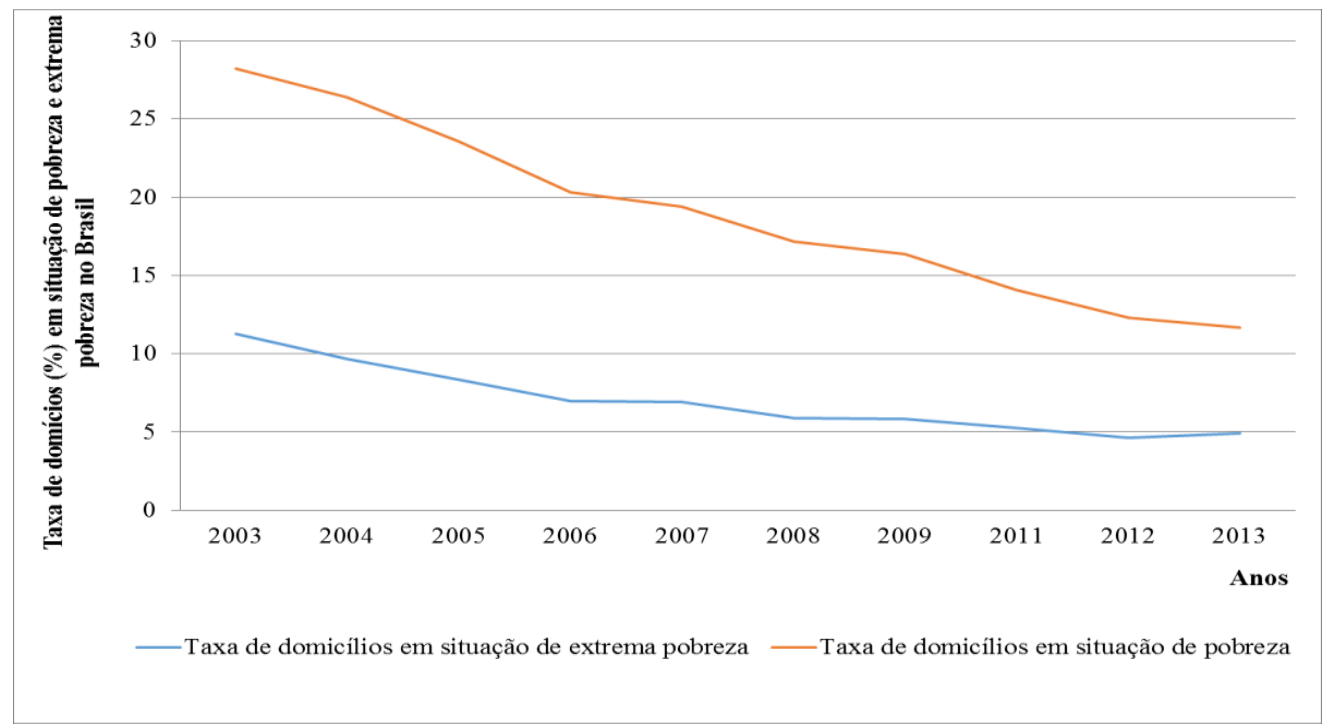

Fonte: Adaptado de IPEA (2017).

A análise das referidas informações permite identificar que a taxa inicial de domicílios em situação de extrema pobreza no Brasil em 2003 era de 11,27\%, passando a 4,64\% em 2012, em uma queda contínua durante o período. Entretanto, houve entre 2012 e 2013 um pequeno aumento da taxa de domicílios em situação de extrema pobreza (4,92\%). No mesmo período de tempo, em 2003, a taxa de domicílios em situação de pobreza era de 28,20\% e, em 2013, o percentual caiu para $11,67 \%$. 
Com base nas informações supramencionadas, é possível inferir que a efetividade do Programa Bolsa Família sobre o combate da extrema pobreza foi maior do que sobre a pobreza. Percebe-se que a queda dos indicadores de extrema pobreza foi mais acentuada no período analisado e o comportamento dos indicadores de pobreza ficou praticamente estagnada a partir do ano de 2008.

Em tese, pode-se observar que nos primeiros catorze anos do PBF muitos brasileiros deixaram a condição de extrema pobreza, isto é, a condição de miséria e passaram para o patamar da pobreza. Assim, há indícios de que o programa foi importante estratégia em termos de política pública para combate da situação de vulnerabilidade social e econômica dos beneficiários.

De acordo com os dados do IPEADATA (2017) e da PNAD (2013), evidencia-se que houve uma redução continuada da pobreza entre 2003 e 2013. A linha utilizada para identificação dos indivíduos pobres se refere ao dobro da linha de extrema pobreza. Assim sendo, considera-se R $\$ 140$ reais como balizadores para a linha de pobreza e R\$ 70 como balizadores para a linha de extrema pobreza, valores atualizados até 2013. Vale mencionar que estes valores estão associados ao cálculo realizado pela PNAD/IBGE, correspondentes ao valor de uma cesta de alimentos com o mínimo de calorias necessárias para suprir, de forma adequada, uma pessoa, segundo as recomendações nutricionais da Food and Agriculture Organization (FAO) e da Organização Mundial da Saúde (OMS).

A figura 02 apresenta o percentual de indivíduos em situação de pobreza extrema no Brasil entre os anos de 2003 a 2012. 
Figura 02 - Taxa de extrema pobreza no Brasil entre os anos de 2003 a $2013^{9}$

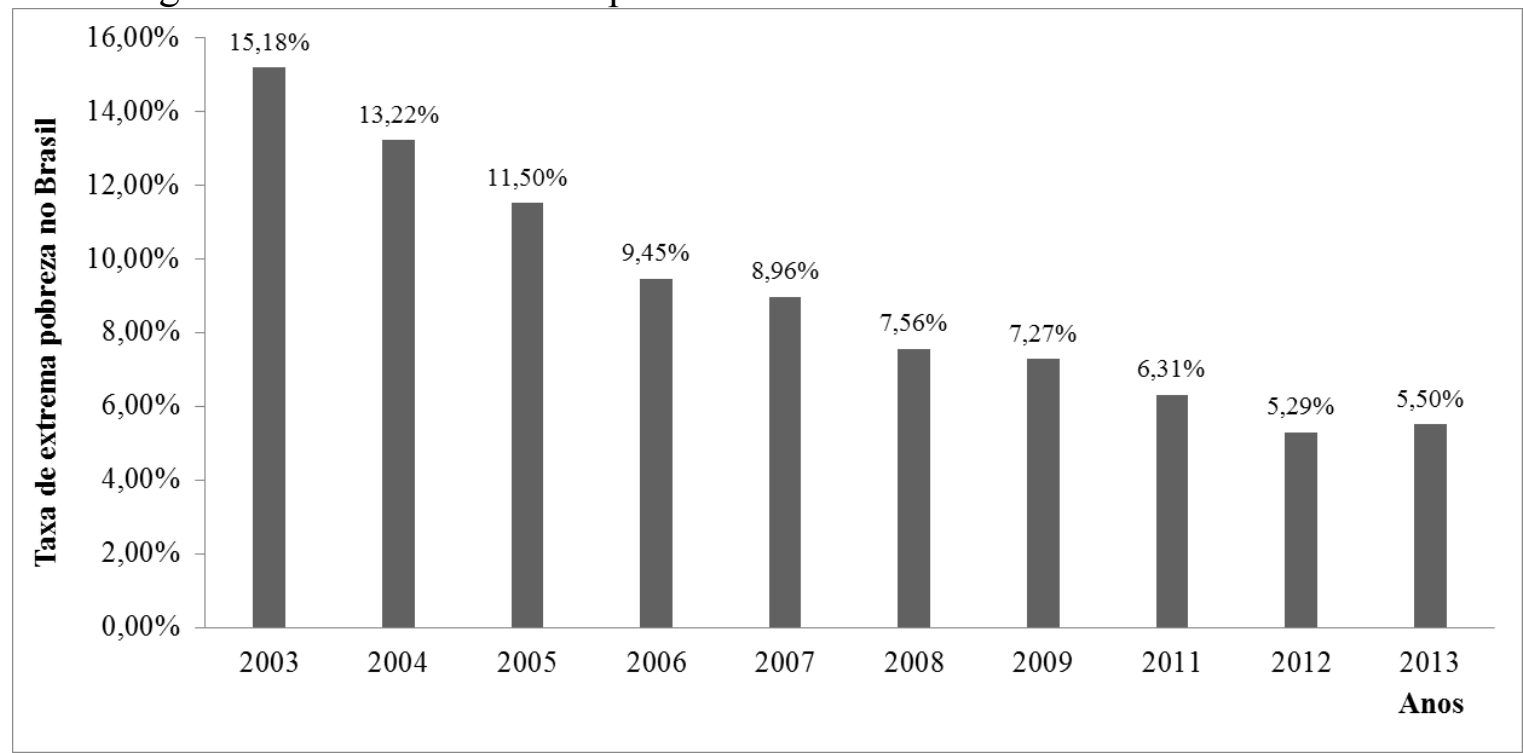

Fonte: Adaptado de IPEADATA (2017).

Percebe-se que houve uma redução percentual média da taxa de extrema pobreza no Brasil de 1,23 entre os anos analisados, com um aumento da taxa em 2013. Nota-se ainda que é constante a redução do patamar inicial de pobreza, a considerar o ano de 2003 com parâmetro, em que a taxa era de 15,18\% de elegíveis cobertos na situação de extrema pobreza no Brasil para, em 2012, uma taxa de 5,29\%. Estudos apontam que este resultado está ligado diretamente ao aumento de famílias beneficiadas pelo PBF que, neste primeiro momento, condiz à estratégia de auxiliar "os mais pobres dentre os pobres" no combate à extrema pobreza no Brasil.

Ao longo do tempo, o PBF começou a ser aprimorado, podendo a cada ano, atingir um maior número de famílias. Acompanhando este crescimento, o número de famílias cadastradas na base do programa também aumentou, como consequência da maior abrangência e dos aprendizados adquiridos pelos agentes envolvidos na gestão das atividades do PBF. Segundo o IPEA (2014), o Brasil mantinha historicamente uma taxa de pobreza de aproximadamente $34 \%$ desde 1995 , e esse número começou a cair a partir de 2004, o que pode ser compreendido no reflexo das políticas sociais adotadas pelo Governo Federal, inclusive e primordialmente pelo Programa Bolsa Família.

A despeito das críticas do Programa Bolsa Família, muitas famílias brasileiras deixaram a situação de extrema pobreza e vem garantindo o direito à cidadania e o acesso aos direitos elementares. As condicionalidades vinculadas à matrícula das crianças na escola, ao

\footnotetext{
${ }^{9}$ Os dados foram extraídos da base do IPEADATA e deve-se notar que o ano de 2010 não entra no cálculo por ser ano de CENSO Demográfico. Portanto, para que não haja cruzamento de informações com a base de dados da PNAD, este ano fica excluído no que se refere ao estudo da população.
} 
acesso a serviços de saúde também contribuem para que a população brasileira mais vulnerável possa romper com o ciclo de reprodução automática da pobreza.

Conforme argumenta Sen (2010), a pobreza não pode ser mensurada e limitada apenas à condição econômica das famílias. As condições de vida das pessoas e suas capacitações dependem de outros fatores mais abrangentes, dentre estes, o contexto socioeconômico do ambiente estudado, além dos fatores absolutos e relativos. Por isto, a realização de pesquisas que possam demonstrar os desafios ainda a serem superados pelas políticas sociais em direção ao desenvolvimento humano é fundamental.

\section{AVANÇOS E DESAFIOS PARA O DESENVOLVIMENTO HUMANO DO BRASIL}

A abordagem das capacidades, desenvolvida por Sen (2010), define a situação do indivíduo em relação às suas possibilidades em exercer suas liberdades, fazendo com que seus direitos sociais, civis e políticos sejam respeitados. Segundo o autor, o caráter multidimensional da pobreza cria a necessidade da obtenção de um indicador mensurável, uma abordagem plural levando em consideração uma situação autoavaliada, como o indivíduo percebe sua própria situação social.

A abordagem multidimensional da pobreza vai além da noção das necessidades básicas, incorpora também o acesso ao sistema de educação, saneamento, saúde dos indivíduos, entre outros, com a inclusão do exercício das necessidades de representatividade social e do uso da cidadania do indivíduo (ROCHA, 2006). Dada a natureza do fenômeno da pobreza e suas influências sobre o processo de desenvolvimento, busca-se nesta seção analisar a evolução de indicadores de desenvolvimento humano no Brasil.

Criado na década de 1990 por Mahbub ul Haq e Amartya Sen, o Índice de Desenvolvimento Humano (IDH) é responsável por medir o desenvolvimento humano de determinada localidade geográfica com base na análise de três componentes básicos:

a) A longevidade do indivíduo, medida pela esperança de vida ao nascer, refletindo as condições de saúde e salubridade da população estudada;

b) A educação, medida por uma relação entre a taxa de alfabetização de adultos com a combinação da taxa de matrícula nos níveis de ensino fundamental, médio e superior; 
c) A renda, que é medida pelo poder de compra da população transformado em um índice universal (pela Paridade do Poder de Compra) para que possa ser comparável entre países a uma mesma base (SANTOS, 2007);

De maneira geral, a disposição dessas três dimensões compõe um único índice. $\mathrm{O}$ cálculo do IDH é realizado a partir da média simples entre os indicadores variando entre zero (nenhum desenvolvimento humano) e um (total desenvolvimento humano), podendo ser classificados como:

- IDH entre 0 e 0,499: baixo desenvolvimento humano;

- IDH entre 0,5 e 0,799: médio desenvolvimento humano;

- IDH entre 0,8 e 1: alto desenvolvimento humano;

A figura 03 apresenta a evolução do IDH estimado para o Brasil entre os anos de 1990 a 2015. Destaca-se que no ano de 1990, o Brasil ocupava a 59a posição dentre os países com maior desenvolvimento humano. Por mais de vinte anos o país galgou avanços nas diferentes dimensões componentes do IDH.

Ainda, o IDH brasileiro era 0,79 em 2004 , ocupando a $63^{\circ}$ posição no ranking mundial, sendo considerado um desenvolvimento humano médio. Em 2013, o Brasil obteve um IDH de 0,74 , ocupando a $79^{\circ}$ posição no ranking mundial evidenciando uma queda de posicionamento em relação aos demais países (PNUD, 2016). O último estudo realizado aponta que o Brasil continua na posição $79^{\circ}$, mas seu desempenho no tocante ao indicador social reduziu de 0,754 para 0,561 .

Figura 03 - Evolução do Índice de Desenvolvimento Humano do Brasil (1990 - 2015)

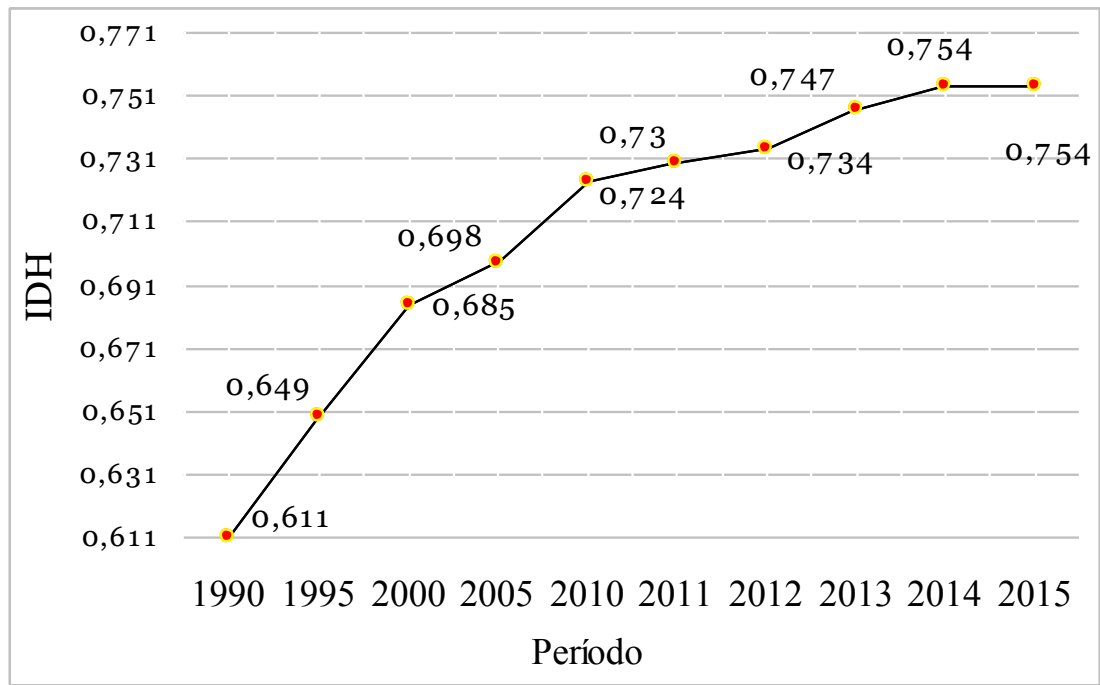

Fonte: Adaptado de PNUD (2017). 
Argumenta-se que o fato de o IDH brasileiro apresentar um resultado negativo no que tange a dimensão social é bem preocupante. Na prática, o desenvolvimento humano não está ocorrendo de maneira ampla, indicando que nem todos os indivíduos estão tendo suas liberdades políticas, sociais, culturais e de cidadania colocadas em prática.

A existência de intensas desigualdades sociais pode ser a justificativa pela qual o Brasil enfrenta tantos desafios no que tange ao desenvolvimento humano. Cita-se a discriminação salarial por gênero, a discriminação étnica e a discriminação regional como obstáculos em direção ao desenvolvimento humano. Sobretudo, estas são influenciadas pelas condições econômicas atuais, pelo cenário de instabilidade política e também pela herança histórica de alguns preconceitos, como a própria naturalização da pobreza e da desigualdade.

Ainda no final do século XX, Andrade (1989) afirma que a sociedade brasileira estava disposta a perpetuar e reproduzir a pobreza, pois a grande maioria das pessoas no país são trabalhadores e pobres. Uma passagem do autor ainda mais crítica sobre o assunto, afirma que “(...) fixam os pobres em sua condição, de tal forma que os estes mesmos se reproduzam, como num jogo de espelhos, as condições institucionais da sua existência".

Accorssi et al. (2012) afirmam que a pobreza é considerada muitas vezes como fenômeno natural e inerente ao processo de interação social. Da mesma forma, Castel (2001) e Paugam (2003) tratam a pobreza e a desigualdade social como fenômenos imutáveis. Estas concepções minam os agentes sociais de privações que, por consequência, tornam-se obstáculos ao desenvolvimento humano.

De maneira geral, os estigmas sociais podem desencadear sentimentos de vulnerabilidade e insegurança das pessoas em situação de vulnerabilidade, então, a pobreza pode ser encarada como um fenômeno não isolado por si apenas, mas um efeito que pode causar a reprodução de si mesma. Para Sen (2010), para que uma pessoa saia da pobreza e passe a levar uma vida digna e com bem-estar, ela precisa desenvolver suas capacidades por meio de ações individuais e coletivas, por meio de oportunidades sociais, a fim de romper a reprodução dessa condição.

E é nesta direção que o Brasil contemporâneo deve caminhar. Sob a concepção de pobreza e desenvolvimento, as políticas sociais devem buscar promover a cidadania, a igualdade, o acesso universal aos direitos sociais.

\section{CONSIDERAÇÕES FINAIS}

A literatura acadêmica, que trata da natureza e das causas do fenômeno da pobreza, é vasta e plural. Sobretudo, a abordagem da pobreza relativa ganhou proeminência nas últimas 
décadas, especialmente porque incorpora à análise da pobreza várias dimensões da vida humana e da vida em sociedade.

Em especial, a abordagem das capacidades, desenvolvida por Amartya Sen, vem contribuindo para o entendimento de que não somente os quesitos associados à renda interferem no bem-estar social e na qualidade de vida dos indivíduos. O desenvolvimento da condição de agente, o acesso aos serviços de saúde, à educação, a participação social, dentre outras oportunidades sociais devem ser motivadas para que as privações dos indivíduos sejam minimizadas.

Destarte, as políticas sociais são importantes mecanismos instituídos pelos países no sentido de superação da pobreza e de promoção ao desenvolvimento humano. Contudo, para que tenham efetividade, devem implementar estratégias que compreendam as várias dimensões da vida da população em vulnerabilidade social e econômica.

A análise da evolução das políticas sociais demonstra que, desde a promulgação da Constituição Federal, há previsão legal da garantia de direitos sociais elementares, tais como o acesso aos serviços públicos em saúde e educação. Todavia, é com a criação do Programa Bolsa Família que a população mais pobre do Brasil passa a ser assistida, não somente por meio do instrumento de transferência de renda, mas também porque as condicionalidades do programa permitem com que os indivíduos possam ter acesso a algumas liberdades sociais, econômicas e políticas.

Ao longo dos primeiros catorze anos do Programa Bolsa Família, houve uma queda no número de brasileiros vivendo em pobreza e em extrema pobreza. Os avanços sociais são mais modestos nos anos contemporâneos, resultado este que pode ser reflexo de fragilidades da política.

Os resultados do Índice de Desenvolvimento Humano para o Brasil no último ano apresentam uma deterioração do desempenho do indicador social, que apresentou uma queda expressiva. Dentre os desafios a serem suplantados no processo de promoção do desenvolvimento no país estão as disparidades sociais, a citar, as desigualdades regionais de renda e as desigualdades de gênero. Também se deve promover a desnaturalização da pobreza, encarada em muitos espaços como um fenômeno natural e imutável.

Salienta-se que o debate iniciado nesta pesquisa não esgota o tratamento da temática, sendo assim, há necessidade do aprofundamento das discussões. Julga-se importante a realização de estudos que possam retratar com maior propriedade o perfil e alcance das políticas públicas no país. A avaliação da natureza das desigualdades sociais e da pobreza, 
bem como a análise das estratégias plausíveis para sua superação, contribuirão para que o desenvolvimento humano e a expansão das liberdades sejam concretizados.

\section{REFERÊNCIAS BIBLIOGRÁFICAS}

ACCORSSI, A.; SCARPARO, H.; GUARESCHI, P. A naturalização da Pobreza: Reflexões sobre a formação do Pensamento Social. Psicologia e Sociedade, v. 24, n. 3, pp. 536-546, 2012.

ANDRADE, R. C. Política e Pobreza no Brasil. São Paulo: Lua nova, 1989.

AZEVEDO, D. C.; BURLANDY, L. Política de combate à pobreza no Brasil, concepções e estratégias. Rev. Katál. Florianópolis v. 13, n. 2, pp. 201-209, jul./dez., 2010.

BRASIL. MINISTÉRIO DO DESENVOLVIMENTO SOCIAL E COMBATE À FOME (MDS). Bolsa Família. Brasília, DF, 2015. Disponível em: <www.mds.gov.br $>$. Acesso em 10 de setembro de 2017.

CARVAlHO, G. F. A Assistência Social no Brasil: Da caridade ao direito. Monografia apresentada ao Departamento de Direito da Pontifícia Universidade Católica do Rio de Janeiro (PUC-Rio) para a obtenção do Título de Bacharel em Direito, 2008.

CASTEL, R. As metamorfoses da questão social - uma crônica do salário. Petrópolis: Ed. Vozes, 2001.

CHAMBERS, R. What is Poverty? Who asks? Who answers? International Poverty Centre Poverty In Focus December, 2006.

CODES, A. L. M. Mensuração da Pobreza: uma reflexão sobre as necessidades de articulação de diferentes indicadores. CADERNO CRH, Salvador, v. 17, n. 40, pp. 129-141, Jan./Abr., 2008 .

CRESPO, A. P. A.; GUROVITZ, E. A pobreza como fenômeno multidimensional. $R A E-$ Eletrônica, v. 1, n. 2, pp. 1-12, 2002.

FAO. Food and Agriculture Organization, 2014. Disponível em: https://nacoesunidas.org/. Acesso em: 22 de setembro de 2017.

HOFFMANN, R. Distribuição de Renda: Medidas de Desigualdade e Pobreza. São Paulo: Ed. USP, pp. 218 - 244, 1998.

IBGE. Instituto Brasileiro de Geografia e Estatística. Pesquisa Nacional por Amostra de Domicílios (PNAD), Rio de Janeiro, 2006, 2012, 2013, 2014, 2015 e 2017. Disponível em: $<$ www.ibge.gov.br>. Acesso em: 9 de setembro de 2017.

. Instituto Brasileiro de Geografia e Estatística. Sintese de Indicadores Sociais: uma análise das condições de vida da população brasileira, Rio de Janeiro, 2012. Disponível em $<$ http://www.ibge.gov.br $>$. Acesso em: 10 de setembro de 2017. 
OIT. International Labour Office. Employment Growth and Basic Needs: A One-World Problem. Report of the Director-General of the International Labour Office, Geneva, 1976.

IPEA. Instituto de Pesquisa Econômica Aplicada. Boletim 23. Políticas Sociais: Acompanhamento e Análise. Assistência Social. Brasília: IPEA, 2015.

Instituto de Pesquisa Econômica Aplicada. Assistência Social: Índice de Desenvolvimento Humano. Brasília: IPEA, 2017.

KERSTENETZKY, C. L. Desigualdade e Pobreza: Lições de Sen. Revista brasileira de Ciências Sociais, v. 15, n. 42, 2000.

KERSTENETZKY, C. L.; MONÇORES, A. É possível acabar com a pobreza no Brasil? Revista Ciência Hoje, v. 54., n. 320, pp. 36 - 40, 2013.

MARTINS, V. Resenha: A Política Social Brasileira no Século XXI: a prevalência dos programas de transferência de renda. Rev. Katál. Florianópolis, v. 10, n. 1, pp. 123-125 jan./jun., 2007.

MOURÃO, L.; JESUS, A. M. Programa Bolsa Família: uma análise do programa de transferência de renda brasileiro. In: Field Actions Science Reports The journal of field

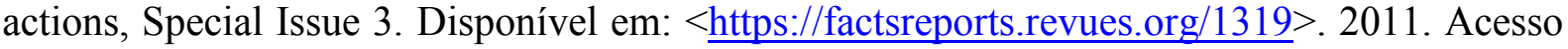
em: 15 de setembro de 2017.

ONU. Organização das Nações Unidas no Brasil. Disponível em: $<$ https://nacoesunidas.org/>, 2015 e 2017. Acesso em: 25 de setembro de 2017.

PAUGAM, S. Desqualificação social: ensaio sobre a nova pobreza. São Paulo: Educ/Cortez, 2003.

PEÑA, C. R.; PINHEIRO, D.S.; ALBUQUERQUE, P. H. M.; FERNANDES, L. M. A eficácia das transferências de renda: as tendências da desigualdade antes e depois do Programa Bolsa Família. Rev. Adm. Pública, v. 49, n. 4, pp. 889-913, jul./ago., 2015.

PNUD. Programa das Nações Unidas para o Desenvolvimento no Brasil. Disponível em: $<$ http://www.br.undp.org/content/brazil/pt/home/library/idh.html $>, 2016$. Acesso em: 5 de setembro de 2017.

ROCHA, S. Pobreza no Brasil: Afinal, do que se trata? 3.ed. Rio de Janeiro: FGV, 2006.

SANTOS, L. M. N. Pobreza como Privação de Liberdade: Um estudo de caso na Favela do Vidigal no Rio de Janeiro. Defesa de Tese - Universidade Federal Fluminense. Niterói, 190p, 2007.

SEN, A. Desenvolvimento como Liberdade. São Paulo: Companhia das Letras, 2010.

. Desigualdade reexaminada. Tradução e apresentação de Ricardo Doninelli Mendes

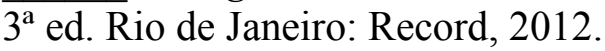

SILVA, M. O. S. O Bolsa Família: problematizando questões centrais na política de transferência de renda no Brasil. Ciênc. saúde coletiva, Rio de Janeiro, v. 12, n. 6, p. 14291439 ,

Dez.

2007.

Disponível

em: 


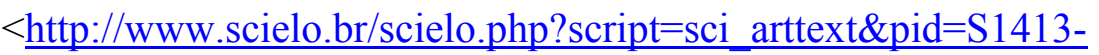

81232007000600006\&lng=en\&nrm=iso $>$. Acesso em: 05 de setembro de 2017.

SILVA, M. O. S.; YAZBEK, M. C.; GIOVANNI, G. A política social brasileira no século XXI: a prevalência dos programas de transferência de renda. 3 Ed.. São Paulo: Cortez, 2007.

TOWNSEND, P. The International analysis of poverty. Conceptualising poverty (Org.) Nova York: Harvester Wheatsheaf, pp. 27-39, 1979.

. The International Analysis of Poverty. Hertfordshire: Harvester Wheatsheaf, 1993.

"What is Poverty? Concepts and Measures". In: UNDP, United Nations Development Programme. Poverty In Focus, 2006. Disponível em: <http://www.ipcundp.org/pub/IPCPovertyInFocus9.pdf >. Acesso em: 11 de setembro de 2017. 